\title{
Introducing "captaining": How to best combine group work with individual achievement within higher education examination
}

\author{
Mirek Dymitrow \\ Chalmers University of Technology / University of Gothenburg / Lund University, Sweden
}

\begin{abstract}
This paper deals with the problem of making group work and individual achievement meet in the context of combined examination at universities. The underlying idea of this research derives from the policy that is increasingly gaining power at many university departments, namely that it is inappropriate to examine students on the basis of group work alone, while at the same time limited departmental resources cannot allow for increasing the number of individual examinations. This paper attempts to square this paradox by elaborating on new ways to individualize compulsory group work so that it fulfils both formal and educational objectives, but also so it feels meaningful, motivative and fair to the students. This multifaceted challenge is captured in a novel methodological approach named "captaining". By drawing on existing theoretical frameworks, own experiences and subsequent evaluation, "captaining" is presented as a promising alternative to the individualism vs. collectivism dilemma, as well as to extra-educational factors impacting the implementation of best examination practices.
\end{abstract}

Keywords: Examination; Group work; Individual task; Captaining

Article History: Submitted 15 June 2019; Revised 22 December 2019; Published online 11 January 2020

\section{Introduction}

This paper deals with the problem of making group work and individual achievement meet in the context of combined examination at universities (Gess-Newsome et al., 2019; Zhi-Xi et al., 2019; Baird et al., 2019). This problem may come to many as something rather straightforward: after completing a course, a student needs to be evaluated that $\mathrm{s} /$ he has learned what $\mathrm{s} /$ he is supposed to have learned. Many will also accept without reservation that there are different ways to achieve just that depending on the scope of the course, two of the most common ones being group work and individual task. While generally true, this principal stance becomes disturbed if the circumstances dictating the choice of examination format are extra-pedagogical (cf. Lenzen, 1997, p. 10), i.e. imparted by external reasons, not part of the constructive alignment between teaching/learning activities and assessment tasks.

\section{Address of Corresponding Author}

Mirek Dymitrow, University of Gothenburg, School of Business, Economics and Law, Department of Economy and Society - Unit for Human Geography, Viktoriagatan 13, 41125 Gothenburg: Sweden.

$\triangle$ mirek.dymitrow@gu.se

0000-0002-6936-342X

How to cite: Dymitrow, M. (2020). Introducing "captaining": How to best combine group work with individual achievement within higher education examination. Journal of Pedagogical Research, 4(1), 57-70. 
One such extra-pedagogical reason is the departments' frail economies. We are living in times of a wider neoliberal approach to higher education which has seen many ramifications and is damaging in many ways. The constant pressure on competitiveness, productivity, research impact, publications, course evaluations and students, has had many university departments struggle to make ends meet, and where saving expenditures has become a major challenge affecting many courses (Rustin, 2016). To this background, courses based on group work are more resource effective and hence cheaper, especially when it comes to examination. By reading and assessing group reports rather than individual assignments, one teacher can turn around greater amount of students in the same amount of time, even more so if the groups are large. Ultimately, at departments with scarcer budgets group work is likely to be the preferred way of examination.

Such conduct, however, comes with its own baggage, namely the many problems associated with unsuccessful group work, most notably: choice of group and ineffective group composition; differing levels of engagement, initiativeness, leadership, resourcefulness and responsibility amongst group members; and many others. Group work is also a matter of fairness, especially if groups are creat-ed by the teacher, i.e. when the student does not get to choose whom s/he wants to collaborate with. This can either be seen as fair (in terms of method of group composition) or as unfair (in terms of outcome). In sum, group work as a learning method can be highly advantageous to some, and equally highly disadvantageous to others. This discrepancy has an inbuilt control mechanism, however; students are likely to react or even protest when their own abilities and achievements are not let forth, are suppressed or taken advantage of by ineffective group members, especially when this affects their grades (as it often does). In such situations, students are likely to invoke more individualism in their curricula (cf. Gava, 2017).

This development has led to a change in policy at several Nordic university departments (but also elsewhere), namely that examinations based on group work alone are unacceptable as a valid form of examination (cf. e.g. TT, 2019; Linköpings Universitet, 2019; Ryegård et al., 2010). However, since the economic impediment stands, this rationale has been realized with a peculiar twist. While individual tasks have indeed been incorporated into the curriculum, it so happens that they still may not be part of the principal examination task, which remains based on group work.

The question that arises is how departments with limited resources can make the most out of group work as the principal way of examination, while truly elevating the role of the individual task, i.e. not merely in a tokenistic manner. This paper wants to tackle that problem by devising and testing a new hybrid approach to group work as an examination form within teaching and learning in higher education.

\section{Theoretical Points of Departure}

\subsection{General teaching assumptions}

The practice of examination in higher education is neither self-evident nor unified but depends on several factors, including metaphysical (e.g. constructivism vs. positivism), philosophical (e.g. individualism vs. collectivism) and pedagogical (e.g. summative vs. formative assessment). All these factors have their associated theoretical frameworks, along with their own assumptions and beliefs about the nature of the human mind, the origins and production of knowledge, as well as the process of learning (Packer \& Goicoechea, 2000; Phillips \& Soltis, 2009). Everybody makes metaphysical assumptions; however, such assumptions can be done more or less explicitly depending on the nature of the subject matter, the degree of establishment of the undertaken approach (hypothesis or method) or simply reflecting the requirements of a particular culture (cf. Dymitrow \& Brauer, 2018).

The principal pedagogical problem underlying this paper is partly rooted in philosophical disparities between individualism (individual task) and collectivism (group work). Individualism is a stance promoting the exercise of one's goals and desires, valuing independence and selfreliance, and advocating that interests of the individual should achieve precedence over those of a 
social group. Collectivism, on the other hand, is the idea that the individual is anchored in the group or society of which s/he is merely a part, and that sacrifice to one's own values and goals should be made for the group's greater good (Craig, 2014). Both stances find reflection in learning activities in higher education: the individual task and the group work. However, questions such as which approach is better or in what ratio they should be combined are much more difficult to answer. Since both have their own appealing rhetorics (self-fulfillment vs. collaboration), they can be used interchangeably to pursue whatever extra-pedagogical reasons might be present.

In metaphysics underlying much of higher education, one of the most fundamental pedagogical challenges is how to compose learning activities that can foster a specific goal by facilitating learning experiences and co-constructing learning with the students to best achieve that goal. This involves eliminating the 'pass-the-exam' mentality (Biggs, 1999; Tynjälä, 1998) by inspiring attitudes towards learning other than merely strategic, as the latter do not nurture critical thinking (cf. Entwistle, 2009). This is particularly true of courses belonging to the social sciences and humanities, which are based on constructivism (cf. Smith \& Brown, 2014).

\subsection{The role of examination}

Examination is a form of assessment intended to evaluate an examinee's knowledge, skills, aptitude or classification in many topics and contexts. It is usually administered in oral or written (sometimes in manual) form. In higher education, examination refers to the "systematic process of documenting and using empirical data on the knowledge, skill, attitudes, and beliefs to refine programs and improve student learning" (Allen, 2004). Such data can be attained from examining student work directly or from assessing the achievement of learning outcomes by way of inference (Kuh et al., 2014). Although examination is often used interchangeably with 'test', its scope extends well beyond the confines of tests, as seen in the development of the educational context of examination after WW2 (Nelson \& Dawson, 2014).

According to Suskie (2004), examination today has become less of a one-time test situation but has evolved into a continuous process, where "assessment establishes measurable and clear student learning outcomes for learning, provisioning a sufficient amount of learning opportunities to achieve these outcomes, implementing a systematic way of gathering, analyzing and interpreting evidence to determine how well student learning matches expectations, and using the collected information to inform improvement in student learning".

Given this breadth, examination remains an important part of higher education. And while it still takes place for formal reasons - to check that the intended knowledge has been achieved, the focus is more on educational reasons - to provide students with information about what they need to learn more about (cf. Elmgren \& Henriksson, 2010, pp. 242-243). Within group work as an examination format - something used more and more often - it is important to understand that distinction, as it can become blurred.

\subsection{Examination within group work}

The major advantage of group work is that the students often feel extra committed and motivated to work. This is because they usually can choose the topic themselves, but they also feel that their work becomes embedded in reality (Elmgren \& Henriksson, 2010; Koohang et al., 2012). Distribution of responsibility is an important aspect of group work that can positively impact group dynamics, changing of roles, and in terms of constant feedback. It is also important from a social perspective, when group members are seen as individuals with their unique predispositions and backsides (Gibbs, 2006).

According to Elmgren and Henriksson (2010) the examination must contain an individual evaluation part. This is not only a (summative) requirement. Group work has several (formative) benefits (after Chris, 2015). Firstly, when a team is put together to handle special projects, the students will always find a way to follow a common direction. Secondly, the ability to share ideas can lead to a more successful project than with several possible approaches being shared. Thirdly, it leads to increased efficiency since the amount of time needed to complete each module 
would be lesser (i.e. Adam Smith's concept of 'division of labor'; Smith, 1776). Fourthly, it enhances the ability for several people to detect flaws about a particular solution or idea. Lastly, in group work the workload can then be distributed in a way that every individual can showcase their various strengths, which also helps the team to tackle areas where the team is weaker (Chris, 2015).

Combining group work with individual assignments in examination is often motivated as a successful way to appeal to and accommodate different preferences, study backgrounds, personalities, etc. (Elmgren \& Henriksson, 2010; West, 2014). There are, however, several problems with group work. Some students work best in collaboration with others in a creative, dialoguebased environment, while others work best when they can concentrate in peace on the study material and their own thoughts (Elmgren \& Henriksson, 2010, p. 90). According to Cain (2012), group work is often overused and some curricula ask that literally all classroom work is to be done in groups. Although collaborative learning does have a place in learning - most students' professional lives will be spent in teams solving problems - a common problem is that many students are introverts who process information quietly and internally.

A second problem with group work is that often it is not done well, as it is difficult to design good instruction for groups. According to Cain (2012) "[p]oorly designed group work (...) can create off task behavior, "learning" of incorrect concepts, wasted time, uneven learning amongst the group, and reinforcement of negative social status markers" (in Pass, 2016). Moreover, the impact of a poorly designed group lesson is likely to be more damaging than that of a poorly designed individual assignment.

Lastly, a common disadvantage with group work is that the students perceive that there is a "hidden curriculum" and, instead of focusing on the project as a learning opportunity, they focus on getting good grades (Wiiand, 1998). Although the rationality behind such an approach can be discussed on a philosophical level, the current results-based discourse (bibliometrics, impact factors, CV boosting, etc.) does reach the students. This becomes particularly problematic with group work as an examination form.

Also, the greater push for group work as an examination form is done sometimes for extrapedagogical reasons (such as limited resources), whereupon the pro-collaborative rhetoric can overwhelm the individualistic aspects of learning, e.g. the rhetoric of the student's future employability, in which teamwork is seen as superior to solitary work (cf. Winka \& Ryegård, 2013). While the literature calls for a balance between group work and individual assignment, it gives little advice how to actually make the two forms meet within one examination occasion (i.e. by not combining two or more different examinations). This suggests a research gap, which this paper attempts to address.

\section{Aim of the Pedagogical Challenge}

The problem balances on competing theoretical stances with regard to teaching and learning on the one hand, and on the reality of departments' economies on the other. In view of the outlined research gap, the overarching aim of this paper is to elaborate on how group work can be best individualized in the context of combined examination in higher education, with a focus on situations when full individualization is not possible due to budgetary restrictions. This will be done by developing and testing a new method provisionally called "captaining", based on theoretical frameworks, own experiences and subsequent evaluation.

Given the background of this project, a disclaimer is in place. It must be emphasized that combining group work with individual task within one examination occasion is not something that should be pursued if extra-pedagogical factors are not an issue. Both methods of examination have separate rationales and are differently suited for different types of course topics, course formats and course assessments. In other words, combining them should be considered a measure of necessity, where making the best of an undesirable situation must be dealt with pedagogically. 
A second disclaimer regards the sheer context of application (see next section), i.e. a course topic that requires empirical work within a discursive framing, and which must be evaluated through a freely written report/paper that requires subjective assessment on the teacher's behalf. In other words, the proposed method, "captaining", is not applicable in contexts where combining group work with individual achievement can be replaced with, for example, automated tests.

\subsection{Context of application}

I have chosen to develop my ideas in the context of an introductory course in human geography entitled 'Geographical Dilemmas' at the University of Gothenburg in Sweden. The course is worth 7.5 hecs, and is mounted into a course block of 30 hecs within the bachelor's program in geography. Although the topic of the course is secondary to the principal pedagogical (methodological) goal of this project, a few words about the content of the course itself are in place. The focus of the course module is on so-called geographical binaries. Geographical binaries (e.g. urban/rural, structure/agency, time/space, culture/economy, local/immigrant etc.) are human (i.e. constructed) categories rooted in old dichotomous imaginaries that defy the contemporary reality of interconnectedness, but which all the same continue to underpin and influence large sectors of societal organization as acceptable guiding perspectives, including spatial planning and development. As binary thinking is rarely symmetrical, the sharp differences are likely to become a basis for conflict. The aim of the course module, thus, is to argue against the domination of polarizing categories and to foster explorations of the middle ground: how to deconstruct binaries and create new hybrid syntheses containing the best elements of both (cf. Cloke \& Johnston, 2005). More specifically, the students' task was to, in groups of five, tackle a geographical binary of their own choice, both theoretically and empirically. This was to be done by anchoring the chosen binary in a real-life phenomenon taking place in socio-economically challenged areas. The specification of geographical area was done upfront by the teacher to create a common setting for all groups, and thus eliminating the repetitiveness of having to account for the context.

In terms of format, the course contained seven teaching and learning elements + assessment:

Element 1 - Introduction and lectures

Element 2 - Division into groups / choice of topics / choice of captains

Element 3 - Literature seminar

Element 4 - Excursion

Element 5 - Group work in progress with supervision

Element 6 - Oral seminar with opposition (on unfinished material)

Element 7 - Writing and submission of group report

Element 8 - Assessment and grading (by teacher)

Five of these elements were mandatory to pass the course ${ }^{2}$, but only the final one, the group report, was to be graded, subject to examination proper. This means that some of the components leading up to the group report were more directly related to it than others. In this paper, I will therefore not focus so much on the components which were more theoretical and therefore unrelated specifically (although thematically) to the group report. Instead, the focus is on the relation between: (a) group work (input) - (b) group report (output) - (c) examination (evaluation).

Since the character of the course aligned with adopting a specific perspective-optics (in line with constructivism), it required a mode of cognitive development other than the traditional model of education based on teaching-memorizing-testing (cf. Greeno et al., 1996)3. This, in turn,

\footnotetext{
${ }^{2}$ If a mandatory element was missed due to extraneous circumstances, there were compensation exercises for elements $1,3,4$ and 6 . The group work $(5,7)$ was the bulk of the course and had to be done (no compensation exercise).

${ }^{3}$ This is particularly important in geography, which gathers students interested in multiple aspects of what falls under the umbrella term "geography", most notably physical geography anchored in a fact-based, positivistic paradigm. It is also in line with the changed character of skills required in a 21st-century reality, in which reflection is a sought-for quality on the job market. In other words, it is not merely what the students know, but what they can do with what they learned at the university that is ascribed value.
} 
sat well with the dynamic of group work, but had to be adapted to strengthen the individual achievement.

\section{2. "Captaining" as a remedy?}

In view of the course's assumption, the methodological challenge was to find effective ways to make group work feel more like in individual assignment while mounted in a larger context rather than having a minor (anonymous) contributory part feeding into a larger project. The idea is to create the basis for a form of two-part commitment: partly for the group project as a whole (group thinking, cooperation) and partly for the individual contribution (understanding the role of one's contribution in a broader context). The rationale of such an approach is to increase the following three aspects:

(1) Strengthening individuality by accentuating each student's own talents and inclinations through freedom of choice;

(2) Instilling a sense of responsibility over one unique part;

(3) Creating preconditions for a win-win situation, in which the student sees the sense of investing in both the individual part and the group work as a whole.

These aspects can be further helped by ensuring the following:

(4) Protecting the individual against group-induced failure;

(5) Protecting the group against individual-induced failure.

To capture these initial assumptions I have devised a method called captaining. Captaining is based on constructivist presumptions, creating an educational "reality" that meets the students' constructed roles in a social setting, which the exercise tries to replicate.

In short, group work (conducted in groups of 5 students) was divided into five parts (sections), each of which could be said to represent one of the basic parts of conventional academic research procedure: (1) introduction/background, (2) theory, (3) method, (4) data analysis, (5) discussion/conclusion. At the same time, a system of 'captains' (or task managers) was developed; meaning that one captain per each of the five parts would be in charge of leading that specific part (corresponding to 1.000-1.200 words in the final group report). Consequently, each captain was to be solely responsible for that specific part (s/he will be examined only for it), while the whole group is encouraged to contribute to each part. To achieve this, special criteria were designed that would create an effective system of reciprocity, leading up to a combined group/individual task.

\subsubsection{Strengthening individuality by accentuating each student's own talents and inclinations through} freedom of choice

Hammar Chiriac and Granström (2012) argue that leadership in teaching is not a binary hands on/hands off approach, but requires individual assessment of each and every group member's capabilities in specific, with shifting priorities based on the individual's needs. In this vein, the students in my project, instead of choosing groups, got to choose their areas of expertise based on the(ir) principal skills beneficial for successfully conducting the five aforementioned parts. To further assist students with the introspection needed, but also to help contextualize what these parts mean in practice ${ }^{4}$ I have created simplified labels for each responsibility section (skills), alongside bullet-point descriptions of qualifications (Table 1).

The students were then given some time (45 minutes) to reflect and then asked to put their names on one of the five lists prepared for each captain role. It is important to stress that each student can only sign up for one list, as ignoring this would create complications and time wasting trying to square confusion.

${ }^{4}$ Not all students were familiar enough with the conventional structure of an academic text, as many of them have not yet gotten to write their first thesis. 
Table 1.

Captaining: the preparation phase. Providing pedagogical support through labelling, responsibility assignment and qualifications

\begin{tabular}{|c|c|c|}
\hline Label & Responsibility section & Qualifications \\
\hline $\begin{array}{l}\text { Captain 1: } \\
\text { "The planner" }\end{array}$ & $\begin{array}{l}\text { Responsible for finding an interesting research topic, } \\
\text { which should be delimited to be feasible within a } \\
\text { short period of time, but also relevant to investigate } \\
\text { from a discursive perspective and be researchable via } \\
\text { interviews. }\end{array}$ & $\begin{array}{l}\text { - Good creativity; } \\
\text { - Good planning ability } \\
\text { (time, resources, } \\
\text { workloads) } \\
\text { - Good at predicting } \\
\text { problems }\end{array}$ \\
\hline $\begin{array}{l}\text { Captain 2: } \\
\text { "The } \\
\text { philosopher" }\end{array}$ & $\begin{array}{l}\text { Responsible for making good use of previous } \\
\text { knowledge: finding publications (articles, book } \\
\text { chapters), isolating what is the most important in } \\
\text { each publication, and being able to predict how } \\
\text { previous knowledge can be applied in concrete work. }\end{array}$ & $\begin{array}{l}\text { - Good creativity; } \\
\text { - Good ability to handle } \\
\text { abstract material } \\
\text { - Good at transforming } \\
\text { the abstract into the } \\
\text { concrete }\end{array}$ \\
\hline $\begin{array}{l}\text { Captain 3: } \\
\text { "The fixer" }\end{array}$ & $\begin{array}{l}\text { Method } \\
\text { Responsible for collecting empirical material (data): } \\
\text { finding suitable informants (scheduling } \\
\text { appointments, approaching strangers), preparing the } \\
\text { questions (asking the "right" questions in view of the } \\
\text { research aim, understanding the importance of verbal } \\
\text { expression); at interviews, controlling the "human } \\
\text { factor" (being responsive, pleasant, inspiring - at the } \\
\text { same time critical and reflexive). }\end{array}$ & $\begin{array}{l}\text { - Good practical skills; } \\
\text { - Good social skills; } \\
\text { - Good flexibility (can } \\
\text { adapt adversity to new } \\
\text { solutions) }\end{array}$ \\
\hline $\begin{array}{l}\text { Captain 4: } \\
\text { "The analyst" }\end{array}$ & $\begin{array}{l}\text { Data analysis } \\
\text { Responsible for processing the collected data } \\
\text { material: to notice structures and connections within } \\
\text { the material, to generalize these structures and } \\
\text { connections; to see these generalizations as part of a } \\
\text { larger context (e.g. in previous research). }\end{array}$ & $\begin{array}{l}\text { - Thorough and focused; } \\
\text { - Good abstraction } \\
\text { ability; } \\
\text { - Has a sense of logic, } \\
\text { language and symbolism }\end{array}$ \\
\hline $\begin{array}{l}\text { Captain 5: } \\
\text { "The holistic" }\end{array}$ & $\begin{array}{l}\text { Responsible for processing the collected material: } \\
\text { isolating the most important part of each component } \\
\text { (aim, theory, method and results) and combining it } \\
\text { into a coherent whole; bringing the isolated } \\
\text { components into an interesting and reflexive } \\
\text { discussion; from the discussion, isolating the most } \\
\text { important conclusions (in view of the aim of the } \\
\text { task). }\end{array}$ & $\begin{array}{l}\text { - Good creativity; } \\
\text { - Understands that things } \\
\text { are always components } \\
\text { of a larger context (and } \\
\text { can apply this) } \\
\text { - Understands the main } \\
\text { theme of the research and } \\
\text { can stick to it, even in a } \\
\text { complex work }\end{array}$ \\
\hline
\end{tabular}

\subsubsection{Instilling a sense of responsibility over one unique part}

Departing from the students' choices, I have then composed the groups. I refrained from letting the students create their own groups to further accentuate the professional (skills-wise) aspect of the exercise. Entering a group as an "expert" with special skills was thought to instill a sense of 
responsibility over one's unique part, both towards oneself and the group, and potentially also to create a common sense of making up a strong, well-composed group of different capacities.

Shortly upon creation, the groups were let to congregate, get to know each other better, and importantly - to jointly select the topic of their research (with the help of a document I prepared, with some suggestions).

3.3.3. Creating preconditions for a win-win situation, in which the student sees the sense of investing in both the individual part and the group work as a whole

An important part of the method was paying attention to how the individual sections (responsibility sections) were to be assessed, both qualitatively (criteria of evaluation, Table 2) and quantitatively (number of points awarded, Table 3 ).

In terms of criteria of evaluation, firstly, these were designed so they could be applied universally, i.e. for each kind of captained section, each being notably different. Upon assessment, each section was to be evaluated according to the abovementioned four criteria, with each criterion being worth 0-3 points, giving a possible maximum of 12 points per student. The points were to be graded as shown in Table 3, some accompanied by specific measures.

Table 2.

Criteria of evaluation and explication of output expectations.

\section{Criteria of evaluation Explication: what aspect was targeted?}

(1) The section constitutes a well-grounded Incentive for investing in group work part of the report as a whole

(2) The section has a logical structure and Formalities, general academic requirements line of argumentation

(3) The deliberated content is relevant for the Incentive for investing in individual work chosen research topic

(4) The focus of the content has a clear Meeting the posited course aim discursive alignment

Table 3.

Grading of the individual sections of the group report with regard to accumulated points.

\begin{tabular}{cll}
\hline Points & Grade & Measures \\
\hline $10-12$ & PD (pass with distinction) & Passed the course \\
\hline $7-9$ & $\mathbf{P}$ (pass) & Passed the course \\
\hline $4-6$ & $\mathbf{C}$ (to be completed) & $\begin{array}{l}\text { Requires improvement, particularly in view } \\
\text { of the criteria with the lowest scores }\end{array}$ \\
\hline $0-3$ & F (fail) & $\begin{array}{l}\text { Requires a new individual report or needs } \\
\text { retaking the course at a later date }\end{array}$ \\
\hline
\end{tabular}

Additional restriction:

Besides the grand total of points, the student was required to have at least 1 point for each criterion in order to pass the course (i.e. to obtain a " $\mathrm{P}$ ").

The first criterion ("the section constitutes a well-grounded part of the report as a whole"), worth up to 3 points, is thought to incite time investment in the group work as such and by that obtain the extra points needed for a pass with distinction ("PD"). Conversely, should a student refrain from investing time in group work and instead "go rogue", s/he can still pass the course but will have more difficulty obtaining the "PD" marker, and have more at stake for achieving the minimum pass-marker (" $\mathrm{P}$ "). This was further controlled for by an additional restriction, stating that besides the grand total of points, the student had to have at least 1 point for each of the four criteria in order to pass the course. For instance, a student with 7 points distributed as 
“ $0+1+3+3$ " would not get a " $\mathrm{P}$ " but a " $\mathrm{C}$ " (completions) because criterion 1 was not fulfilled at the most basic level.

\subsubsection{Protecting the individual against group-induced failure}

The same goes for instances of involuntary group problems, i.e. where group work does not function very well; even here, the individual student has considerable control over her/his part as long as some basic group work is developed. Moreover, it is unlikely that more than one or possibly two students in the group would not function well. It is assumed that as long as there is a critical mass functioning, the group task is executable, including criterion 1 (although probably to a lesser degree).

\subsubsection{Protecting the group against individual-induced failure}

The selection of criteria has also an inbuilt reverse mechanism, meaning that a student cannot rely on others doing the work for her/him (the so-called "parasitic students"). Criteria 2, 3 and 4 reflect mostly individual achievement. While criterion 2 reflects a student's general academic abilities and criterion 4 is there to keep the student aligned with the specific aim of the course, criterion 3 gives most room to excel individually by developing one's part to its fullest. This is also in line with the student's initial choice of role in terms of her/his skills, which - if true should come relatively easy. The presupposition is also such that if each student completes her/his part well (and if the communication between students is working on at least a basic level), then criterion 1 should not pose any major problems to fulfill (hence the reverse incentive).

\section{Results and Discussion: Evaluation of the Captaining Method}

\subsection{Pros and cons during the preparation and execution phases}

The division and execution process. Hammar Chiriac and Granström (2012) touch upon difficulties inherent of formulating group work or managing a group project in general, in that the leader (i.e. teacher) is setting the frame for the interaction, and stressing that, "[ $t$ ]he crucial point deals with the teacher's attitude during the group's work" (p. 360). This implies that in general terms the leader needs to structure the groups' (i.e. students) desires, provide a clear structure and to provide feedback and support throughout the whole process. However, with such an approach comes a downside, namely that "the students [take] no responsibility and [do] not learn enough" (p. 360), as too much structure and micromanagement squashes creativity, independent thought and discourages taking responsibility. In that sense, being a successful teacher is not only about setting structures, but also allowing for enough independence for the group members (i.e. students) to take responsibility for their own actions. With captaining as a method, the idea of students choosing their areas of responsibility as well as the process of dividing students into groups went surprisingly smoothly. From this, I gather that my initial assumptions about responsibility and expertise worked out well. By letting each student choose the part s/he felt best at, ignited visible motivation and respect for one's presence in the group, and greater care for the task.

Distribution of captains. One, howbeit minor, challenge was the need to obtain the same amount of captains for each task in order to compose even groups. Indeed, some captain tasks attracted slightly more volunteers than others (especially the analysts where a bit underrepresented). I resolved that by raising the issue of surplus/deficit openly in class, asking whether anybody from the surplus pots could consider walking over to a deficit pot. This proved much easier than expected, probably due to several students having more strengths than one.

Group formation. A similar problem occurred with there being too few or too many students to form even groups of five. I was prepared for that, stipulating that with a minor surplus (six students per group), the doubled section could be subdivided into two, more profiled, in-depth sections, rather than letting two students work on one common part, as this would counteract the 
suppositions of the captaining method. In the case of deficit, I offered the students writing the "absent" part jointly, just so there would be no gap in the report's narrative, and so that the remaining parts would make sense. No one would be assessed for that captain-less part. In fact, some students stated they would prefer working in groups of fewer students.

Handling drop-outs. In one case, one student dropped out during the group work, but late enough to have contributed markedly to his part, so it did not interfere with the group work's execution. It did, however, affect the writing of the report and the associated presentation seminar. In this particular case, I proceeded as described in the paragraph above. I deemed it was not a big problem for the group to put together such a symbolic text due to its relative brevity (1.000 words), the division of labor between four members, as well as the fact the all group members were (nominally) to be equally engaged in the group work as a whole and therefore had to have basic knowledge of all stages/components of the group work.

Distribution of labor as counterintuitive to student learning? One final remark should be raised regarding how distribution of labor (i.e. the profiled captain roles) plays out in the context of higher education. As mentioned in section 2.3, specialization, while it enhances work efficiency, it at the same time narrows down one's pool of competencies to that of depth rather than breadth (cf. Bowden \& Marton, 1998). As Bateman (2015) put it, " $[\mathrm{w}]$ hether it is crossing disciplines, breaking down silos, or thinking outside the box, everyone is talking about boundary spanning as the key to solving the world's toughest problems". And while depth (or expertise) as an orientation is more readily adopted in performance-oriented tasks (due to efficiency of execution), breadth is the preferred solution when one's input is seen as "an opportunity to learn" (Bateman, 2015). This signals a dilemma whether the student should be encouraged to perform things $\mathrm{s} /$ he is already proficient in or to engage in activities outside of her/his comfort zone. Obviously, there are benefits with both approaches, and in higher education both are supported. However, given the context of the discussed pedagogical challenge (combining group work with individual achievement as a measure of necessity, not because it is intrinsically good), I draw that further complicating the procedure would create more problems than benefits. Most apparently, the rationale of students entering groups as "experts" would be lost, and the group work would be seen more as a form of "sophisticated punishment": the students are supposed to do things they are necessarily not good at, they cannot choose their own groups, and they are subjected to entrust fellow students which are also forced to perform tasks they are not good at. And lastly, how would the teacher elicit honest statements from students about what they are "bad" at in an attempt to convince them that this is good for their development? Clearly, not only would this not work, but it would also easily turn into a question of pedagogical ethics (where is the boundary for what is fair to ask the student?). One possible way to circumvent this impasse could be to alternate the students' captain roles upon each consecutive time captaining is used as a method within the same class. The procedure would mimic the standard one described in section 3.2.1, i.e. the students would choose their skills themselves; however, an additional restriction would be added: they would not be able to choose the role they had the last time. This would probably work, as most people have more than one skill at their disposal.

\subsection{Pros and cons after report assessment and student feedback}

Having assessed and graded the 49 individual student contributions distributed between ten group reports, but also having listened to students during a course evaluation seminar, a number of pros and cons could be distinguished.

Overall better performance. The most prominent observation is that the reports were of significantly higher quality compared to how the students had performed in previous contexts. Whether this was due to the captaining method or due to student's progression is impossible to determine, even if it is tempting to believe that the method had at least some role in it. 
Proneness towards favoring the individual task. Elmgren and Henriksson (2010: 241) emphasize the constructive link between goals, learning activities and examination, arguing that if "the examination is not in line with what happens otherwise during the course, the students will devote themselves to the activities that lead to they pass the exam". In several cases, this also became apparent in the group work based on captaining. Having read the ten reports, my impression was that the students had cooperated mainly during the empirical stage, i.e. when everyone had vested interest in acquiring enough data for the report to materialize. After this, most students focused on their own part, as they knew that that particular part would be subject to individual assessment. The first criterion (that "the section should constitute well-grounded part of the report as a whole") did not always work well, as certain arguments were repeated and/or mentioned in "wrong" parts of the report (e.g. results in the introduction section or method in the discussion section). This implies (perhaps) that the students did not fully trust each other that some crucial statements will be elaborated, and instead took the risk of moving beyond the agreed-upon scope of their respective parts, disregarding the distribution of labor.

Dependability of succession. One major problem came with those parts which were directly reliable on the preceding parts. For instance, "the analyst" cannot successfully complete her/his task if "the fixer" does not deliver the data material, or "the holistic" is unable to provide a discussion if "the analyst" does not provide an analysis or if "the philosopher" does not provide a theoretical framework to discuss the data against. On the contrary, "the planner" is much more at ease devising his/her part, as the introduction is technically unaffected by what comes after it (save for with regard to criterion 1). Basically, the further ahead the chronology of the report, the harder it gets to get it right if the preceding parts do not function well. Still, as the exercise proved, this happened only in a few isolated cases, and even then could be circumvented by early student intervention through my involvement. To prevent this from happening, the students should be encouraged to report major collaboration problems early on, so the problem can be resolved either by regrouping or through redistribution of labor.

Fairness of orientation. A potential design problem of the captaining method was that the different parts, by definition, had different orientations. This means that certain parts were more prone to more easily deal with criterion 4 (that "the focus of the content should have a clear discursive alignment"). In this respect, the theory and discussion parts specifically had better "prerequisites" to be held in a discursive tenor than, for example, the introductory or method part. In this respect, I had to constantly pay attention to the context, i.e. the function of a specific part within the report as a whole.

Fairness of difficulty. A similar challenge was in regard to the different parts being of different levels of difficulty, thus posing a potential threat to the fairness of the exercise, as suggested by a couple of students during the introduction. This, however, was quickly resolved through discussion, agreeing that "difficulty" is a subjective quality, depending solely on one's personal strengths and weaknesses. If one is to select a captain role based on their own area of expertise then no part should be too difficult for anyone.

Issues of completion. Another thought concerns grading, specifically the handling of the report parts that did not meet the posited criteria for "pass" (" $\left.\mathrm{P}^{\prime \prime}\right)$ and had to be resubmitted as completions $\left({ }^{\prime \prime} C^{\prime \prime}\right)$. After all, all parts were to be performed by all group members, while the captain's role was to act as a supervisor and main author for her/his specific part. Given this assumption, who were then to make the completions if needed - the captain alone or should some collaboration be allowed? Or perhaps should all group members' (approved) grades remain "frozen" until all report parts have been approved? In the end, I decided to only allow the individual captain to do the completions, but with the option to be able to consult the group members. This is because all group members had an equal chance of using the whole group as a resource during the project period, although I am a bit uncertain whether this was the right choice. As an additional resource 
in this respect, I offered extra tutoring for those who failed to reach the minimum "pass" level upon first try, in fear that they might feel ashamed to go back to the group for assistance, or in the case when the group, reasons notwithstanding, would opt out of helping the student.

Lacking a bonus system? One final issue requiring discussion is whether greater care for the group task as a whole could be more effectively controlled for by enhancing the aspect of reward. As Peel (2017) suggest, it is up to the teachers to maintain student's chief motivative forces behind the learning, arguing that "[v]ital intrinsic motivation may sometimes be supplemented by extrinsic rewards ... regarded as props to support the attention of learners and to augment their interest in the subject matter". Using the famous "carrot and stick" metaphor, the addition of criterion 1 (see Tab. 3 in section 3.3.3) to the assessment had the function of a "stick", where the students had to engage in group work in order to achieve a pass with distinction ("PD") or more points in general. This, as noted in the "Proneness towards favoring the individual task" section above, worked only partially. One way to spawn more motivation for the group work could be by introducing a bonus system, through which each student would get 1 or 2 extra points if the sum of all students' points within one report would amount to $75 \%$ (i.e. 45 points) of the maximum number of points (i.e. 60 ) for each report ( 12 points $\times 5$ students $=60$ points; $75 \%$ of 60 points is 45 points). Such a design would thus work as a "carrot" and hopefully change the students' attitudes.

\section{Concluding Remarks: Making Group Work and Individual Achievement Meet}

Group work is an excellent counterpoint to individual learning in higher education. However, group work is also likely to be the preferred form of examination at educational institutions with scarce budgets. This opens up for a discussion how to make the best of group work by retaining the individual learning objectives. Likewise, the methodological challenge of this paper was to elaborate on potentially effective ways to make group work feel more like in individual assignment while remaining mounted in an overarching group context.

In this paper, I have combined group work and individual achievement in the context of examination through a method called captaining. The pedagogical benefits of this method include: speaking to individuals with different types of learning preferences, study backgrounds, personalities, etc. (Elmgren \& Henriksson, 2010, p. 245; Biggs \& Tang, 2011, p. 14). It is widely acknowledged that some students deliver best in collaboration with others in creative, dialoguebased environments, while others work best when they can concentrate alone on the material and their own thoughts (Elmgren \& Henriksson, 2010, p. 90). This means that even though the actual reasons for the nowadays greater push for group work as the preferred examination form can be considered to be non-pedagogical (especially when limited resources are being redressed into clichés stating that group work is extra important for the student's future employability), there are indeed several pedagogical values in retaining the group work as a valid examination form. But then it is especially important to effectively highlight the individual effort of the student, both its role within the structure of the group work and its representation of the student as an examinable unit (cf. Ayres, 2014). There is also an educational benefit with such a set-up. By being able to choose work tasks which the student sees herself/himself extra good at (also in combination with a self-chosen research topic), it is easier to stimulate greater commitment and sense of responsibility for the project on the part of the student.

Combining group work with individual achievement in the context of examination is admittedly difficult (cf. Bishop-Clark \& Dietz-Uhler, 2012; Perry \& Smart, 2007). However, the problem does not necessarily lie in the difficulty of designing a form of examination that includes both parts. Instead, there are indications that as soon as an individual part is included in a group work, the student tends to focus primarily on the individual aspect (cf. Ramsden, 2003, p. 182) to the detriment of the group work as a whole. This psychological tendency is difficult to handle in practice (cf. Chevalier et al., 2009) since the group work report, as the final product, loses momentum due to this insistence; the content becomes easily repetitive and poorly structured. By bridging this inclination and by investing more time in the beginning for in-class discussion is 
likely to instill a deeper understanding of the course as a pedagogical project: by highlighting the benefits of co-production and the security of failed co-production. This, then, can bring forth the best of each student's part by making the students feel safe in the well-defined frames that have been set up. In three out of ten groups involved in this specific project, it was obvious that the students had worked in this way: the final result was exceptionally good.

Group work is always de facto a mix of individual contributions, but these are seldom readily discernable if the right pedagogical measures are not undertaken. More pedagogical tools are needed to convey the importance of balancing group work with individual efforts within one and the same examination. There seem to be premises for such a balance to be both possible and achievable, but how this should be communicated to the students is a different opening that requires more research.

\section{References}

Allen, M.J. (2004). Assessing academic programs in higher education. San Francisco: Jossey-Bass.

Ayres, R. (2014). Lecturing, working with groups and providing individual support. Fry, H., Ketteridge, S. \& Marshall, S. (eds.): A handbook for teaching and learning in higher education. Enhanced academic practice, (4 $4^{\text {th }}$ ed., pp. 94-106) New York: Routledge.

Baird, J.A., Caro, D., Elliott, V., El Masri, Y., Ingram, J., Isaacs, T., Pinot de Moira, A., Randhawa, A., Stobart, G., Meadows, M., Morin, C. \& Taylor, R. (2019). Examination reform: impact of linear and modular examinations at GCSE. Oxford: OUCEA.

Bateman, T. (2015). Breadth vs. depth: Why some researchers are inclined to span boundaries, others to remain within them. Retrieved March 2015 from https:/ / www.sciencedaily.com.

Biddle, C. (2012). Individualism vs. collectivism: Our future, our choice. The Objective Standard, 7(1), 19-28.

Biggs, J. (1999). What the student does: Teaching for enhanced learning. Higher Education Research $\mathcal{E}$ Development, 18(1), 57-75.

Biggs, J. \& Tang, C. (2011). The changing scene in university teaching. In: Biggs, J., \& Tang, C. Teaching for quality learning at the university (4th ed., pp. 1-14). New York: Maidenhead.

Bishop-Clark, C. \& Dietz-Uhler, B. (2012). Engaging in the scholarship of teaching and learning. Virginia: Stylus Publishing, LLC.

Bowden, J. \& Marton, F. (1998). The university of learning. Beyond quality and competence in higher education. London: Kogan.

Cain, S. (2013). Quiet: The power of introverts in a world that can't stop talking. Portland: Broadway Books.

Chevalier, A., Gibbons, S., Thorpe, A., Snell, M. \& Hoskins, S. (2009). Students' academic self-perception. Economics of Education Review, 28(6), 716-727.

Chris, J. (2015). 7 pros and cons of group work. Driving Business Connection. Retrieved June 2018 from http://www.josephchris.com/7-pros-and-cons-of-group-work.

Cloke, P., \& Johnston, R. (2005). Deconstructing human geography's binaries. In: Cloke, P., \& Johnston, R. (2005). Spaces of geographical thought: Deconstructing human geography's binaries (pp. 1-20). London/Thousand Oaks/New Delhi: Sage.

Dymitrow, M. \& Brauer, R. (2018). Meaningful yet useless? Factors behind the retention of questionable concepts in human geography. Geografiska Annaler: Series B, Human Geography, 100(3), 195-219.

Elmgren, M. \& Henriksson, A.-S. (2010). Universitetspedagogik. Lund: Studentlitteratur.

Entwistle, N. (2009). Teaching for understanding at university: Deep approaches and distinctive ways of thinking. London: Palgrave Macmillan.

Gava, T. (2017). Urge college students to adopt more collectivist practices. Retrieved October 2017 from https://www.thejustice.org/article/2017/10/urge-college-students-to-adopt-more-collectivist-practices.

Gess-Newsome, J., Taylor, J.A., Carlson, J., Gardner, A.L., Wilson, C. D., \& Stuhlsatz, M.A. (2019). Teacher pedagogical content knowledge, practice, and student achievement. International Journal of Science Education, 41(7), 944-963.

Gibbs, G. (2006). Learning in teams: A student guide. Oxford: The Oxford Centre for Staff Development.

Greeno, J.G., Collins, A.M. \& Resnick, L.B. (1996). Cognition and learning. In D.C. Berliner \& R.C. Calfee (eds.), Handbook of educational psychology (pp. 15-41). London: Prentice Hall. 
Guba, E.G. and Lincoln, Y.S. (1994). Competing paradigms in qualitative research. In: Denzin, N.K. and Lincoln, Y.S. (eds.), The SAGE Handbook of qualitative research (pp. 105-117). Thousand Oaks: Sage.

Hammar Chiriac, E. \& Granström, K. (2012). Teachers' leadership and students' experience of group work, Teachers and Teaching, 18(3), 345-363.

Koohang, A., Smith, T., Yerby, J. \& Floyd, K. (2012). Active learning in online courses: An examination of students' learning experience. International Journal of Management, Knowledge and Learning, 1(2), 205-216.

Kuh, G.D., Jankowski, N. \& Ikenberry, S.O. (2014). Knowing what students know and can do: The current state of learning outcomes assessment in U.S. colleges and universities. Urbana: University of Illinois and Indiana University-National Institute for Learning Outcomes Assessment.

Lenzen, D. (1997). Educational science in Germany: Theories, crises, present situation. In: Heyting, F., Koppen, J., Lenzen, D., \& Thiel, F. (eds.), Educational studies in Europe: Amsterdam and Berlin compared (Vol. 1, pp. 1-14.). Providence and Oxford: Berghahn Books.

Linköpings Universitet (2019). Rekommendationer om examination och kursupplägg. Retrieved April 2019 from https://www.student.liu.se.

Morgan, B.M. (2003). Cooperative learning in higher education: Undergraduate student reflections on group examinations for group grades. College Student Journal, 37(1), 40-50.

Nathan, G. (2015). A non-essentialist model of culture: Implications of identity, agency and structure within multinational/multicultural organizations. International Journal of Cross Cultural Management, 15(1), 101124.

Packer, M.J. \& Goicoechea, J. (2000). Sociocultural and constructivist theories of learning: Ontology, not just epistemology. Educational Psychologist, 35(4), 227-241.

Pass, A. (2016). Individual work vs. group work in the classroom. A. Pass Education Group. Retrieved March 2016 from https://apasseducation.com/education-blog/individual-group-work-classroom.

Peel, E.A. (2017). Pedagogy. In: Encyclopædia Britannica (250th Anniversary Edition). Chicago: Encyclopædia Britannica, Inc.

Perry, R.P. \& Smart, J.C. (2007). The scholarship of teaching and learning in higher education: An evidence-based perspective. Dordrecht: Springer.

Phillips, D.C. \& Soltis, J.F. (2009). Perspectives on learning. New York: Columbia University.

Ramsden, P. (2003). Learning to teach in higher education. London: Routledge-Falmer.

Rustin, M. (2016). The neoliberal university and its alternatives. Soundings: Spaces of Resistance, 63, 147-170.

Ryegård, Å., Apelgren, K. \& Olsson, T. (eds.) (2010). A Swedish perspective on pedagogical competence. Uppsala: Uppsala University.

Smith, A. (1776). An inquiry into the nature and causes of the wealth of nations. London: W. Strahan and T. Cadell.

Smith, B. \& Brown, S. (2014). Enhancing student learning through effective formative feedback. London: Routledge.

Solomon, R.C. (2005). Subjectivity. In: Honderich, T. (ed.), The Oxford companion to philosophy (p. 900). Oxford: Oxford University Press.

Suskie, L. (2004). Assessing student learning. Boston: Anker.

TT (2019). Humanister i motvind på universiteten. Retrieved May 2019 from aftonbladet.se.

Tynjälä, P. (1998). Traditional studying for examination versus constructivist learning tasks: Do learning outcomes differ? Studies in Higher Education, 23(2), 173-189.

West, J. (2014). SoTL in teacher education: Layers of learning. New Directions for Teaching \& Learning, 139, 4960.

Wiiand, T. (1998). Examinationen i fokus: Högskolestudenters lärande och examination - en litteraturöversikt. Uppsala: Uppsala Universitet.

Winka, K. \& Ryegård, Å. (2013). Pedagogisk portfölj för karriär och utveckling. Lund: Studentlitteratur.

Zhi-Xi, S., Zhang, L.-J., Yan, S., \& Yan-Ming, L. (2019). Application of group evaluation method in experimental teaching of basic nursing. DEStech Transactions on Economics, Business and Management, ICAEM 2019 edition. 